\title{
SUPPRESSION OF NICKEL RELEASE IN NICKELTITANIUM ALLOYS BY PLASMA IMMERSION ION IMPLANTATION SURFACE TREATMENT: TOWARDS A NEW GENERATION OF "SMART" ORTHOPAEDIC IMPLANTS
}

K.W.K. Yeung1, Y.L. Chan1, S.C.W. Chan1, X.Y. Liu2, C.Y. Chung2, P.K. Chu2, W.W. Lu1, K.D.K. Luk1, D. Chan3, K.M.C. Cheung1

1Division of Spine Surgery, Department of Orthopaedics and Traumatology, Queen Mary Hospital, The University of Hong Kong, Pokfulam, Hong Kong 2 Department of Physics and Materials Science, City University of Hong Kong, Kowloon, Hong Kong 3Department of Biochemistry, Faculty of Medicine, The University of Hong Kong, Pokfulam, Hong Kong

Nickel-titanium shape memory alloys (NiTi) are potentially very useful in spinal deformity correction due to their super elastic properties and their ability to change shape with temperature. However, release of toxic nickel particulate debris remains a major concern. We have developed a novel method of altering the surface of the material to reduce nickel release by using plasma immersion ion implantation (PIII). This study compares the corrosion resistance and mechanical properties of PIII treated samples with untreated NiTi. NiTi discs containing $50.8 \% \mathrm{Ni}$ were implanted with nitrogen using PIII technique. Their elemental depth profile, surface chemical composition, surface hardness and corrosion resistance were compared with untreated NiTi. The amount of Ni released into simulated body fluids after the accelerated corrosion tests were determined. The biocompatibility was assessed by culturing mouse osteoblasts expressing an enhanced green fluorescent protein on the surface of these materials. After PIII treatment, a layer of titanium nitride formed on the surface. Compared to untreated NiTi, the corrosion resistance is better by five times, and the surface hardness and elastic modulus are better by a factor of 2 . The concentration of $\mathrm{Ni}$ in the simulated body fluid for the untreated sample was 30ppm compared to undetectable levels in the PIII treated sample. There was no difference in the ability of cells to grow on either surface. PIII results in enhanced corrosion and wear resistance, and negligible Ni release. This technique will allow NiTi alloys to be safely implanted in the human body. A new generation of "smart" orthopaedic implants will likely result.

\footnotetext{
* Work supported by HK Research Grant Council Central Allocation Vote (CityU\#1/04C), Scoliosis Research Society Standard Investigator Grant, Small Project Funding of The University of Hong Kong, and City University of Hong Kong Applied Research Grant 9667002..
} 